\title{
Guidelines for designing text in printed media for people with low vision
}

\author{
Maja Brozović, Jasmina Alihodžić, Valentina Dunđer, Matea Milin, Josip Bota, Dorotea Kovačević \\ University of Zagreb Faculty of Graphic Arts, Getaldiceva 2, Zagreb, Croatia \\ *E-mail: maja.brozovic@grf.hr
}

\begin{abstract}
Most of the information published through graphic media is designed for people with normal eyesight. There are 285 million people with visual impairment. This number indicates a need for adaptation of the printed media targeted towards this population. World Institute for visually impaired people recommended guidelines for the design of graphic media customized for people with partial blindness. Most of the previous research related to this topic is mostly based on guidelines and characteristics of English and French language in order to enhance legibility of the text for people with low vision. This paper is trying to access the level of legibility of the text for Croatian readers with low vision by analysing parameters such as typeface and letter size, the size of punctuation marks, highlighting style, letter colour and background colour in order to suggest practical guidelines for text design within graphic medias intended for this group of readers. Seven participants from The Zagreb Association for the blind were involved in this study with remaining vision of 2-5\% along with additional eye defects. According to the collected results it is shown that the relation between letter colour and background colour, or better yet contrast has the strongest influence on legibility for people with low vision. Letter size has a weaker impact and the least impact has the type of the typography. The best way of highlighting text is using bold style. The magnification of punctuation marks does not improve legibility. Guidelines for designing printed media on Croatian language for people with low vision can be useful in order to enhance their ability to get information in a same way as other members of society.
\end{abstract}

Key words: low vision, elderly, legibility, typography, letter size

\section{Introduction}

In many cases, people with low vision have difficulties with reading and this can affect the quality of everyday life. Low vision presents the impossibility to read a printed media or face recognition from a common reading distance of about 40 centimetres. Visual impairment or weaken and blurred vision, age-related macular degeneration (AMD), cataract, and glaucoma are referred to the functional eye defects. Currently, there are approximately 285 million people in the world with visual disabilities and majority of them (about 246 million) are visually impaired. This population is not negligible, so it should not be excluded from the analysis of how much a particular product would meet their needs.
A large number of visual impaired people are elderly. The number of older people is increasing. It is estimated that $13 \%$ of Croatians are older than 65 . Through the years, people change and their cognitive and motoric capabilities decrease. The legibility of text and psychophysical changes suggest that particular characteristics of typography can affect readability and reading acuity of text for people with normal and low vision. Mainly, characteristics of typefaces refer to the type of typography, presence or absence of serifs, letter size, stroke width, leading, kerning and tracking, letter height, colour and contrast between text and background. When assessing the characteristic of typography, the result can depend on differences in legibility that are connected with letter size, lightning 
conditions or design of printed media. Generally, serifs do not affect the reading speed and serif typefaces are no less legible than sans serif typefaces. Differences in legibility occur in the case of small letter size or larger reading distance [1]. Because of the higher $\mathrm{x}$-height and uniform stroke width, the sans serif typography are more legible to older individuals [2]. It is considered that lowercase is more legible than uppercase. However, lowercase is smaller by height and width. According to Arditi and Cho [3], uppercase is more legible than lowercase because of the possibility of using smaller letter size without affecting legibility. This especially refers to readers with low vision.

Most of the research on characteristics of typefaces and their affect on legibility for people with low vision, recommend sans serif typography (Arial, Helvetica, Verdana and Adsans) in 16 to 18 point size to achieve optimal legibility and readability. When using Courier rather than Times New Roman, people with central vision loss can read even smaller point size [4]. For individuals with age-related macular degeneration (AMD) it is suggested to use sans serif typography with variable-space. It is also important that the radius of the rounded letters in sans serif typography is slightly increased and that the punctuation marks are in bold style and accentuated, especially in larger paragraphs.

The American Printing House for the Blind (APH) developed a typography for people with low vision called APHont, sans serif variable-spaced typeface. This typography is intended for large-prints and is free to download. Compared to common typography, as Arial and Times New Roman, APHont is rounder, wider and heavier, with larger cross bars and punctuation marks [5]. The Royal National Institute of Blind People (RNIB), has created Tiresias, a typography for visually impaired people intended for large-print publications [6]. According to the studies conducted by the RNIB, it is also characterized as sans serif, variable-spaced typography [7]. The research carried out by Rubin et al. [8] with individuals with mild-to moderate vision loss caused by glaucoma or cataract showed that different typography (Tiresias, Times New Roman, Foundry Form Sans or Helvetica) adjusted in the same letter size did not affect reading. The Canadian National
Institute for the Blind (CNIB) investigated the characteristics of typefaces intended for people with low vision, were the most of the individuals had age-related macular degeneration (AMD) as a primary diagnosis. Their guidelines suggest the use of Arial or Verdana, sans serif proportionally spaced typography [9].

Tarita-Nistor et al. [7] investigated the reading performance of patients with the same diagnosis by using four typography: Times New Roman, Courier, Arial and Andale Mono (proportionally or variable spaced, serif or sans serif). Findings have shown a significant effect of typeface on reading acuity, but did not affect reading speed and critical letter size. Between the typography, Courier has shown the best result for reading small letter, while reading speed was the slowest in the case of Arial. Despite suggestions by the associations for blind people, authors conclude that typography like Arial are not useful for people with age-related macular degeneration (AMD).

The research related to evaluation of leaflets designed according to the various criteria recommended from $\mathrm{CNIB}, \mathrm{RNIB}$ and $\mathrm{APH}$ guidelines were conducted by Chubaty et al [10]. They evaluated and described the design of 388 health leaflets intended for elder people, displayed in clinics and pharmacies in Edmonton, Canada. Several leaflets collected for the research were made completely according to the suggested guidelines, while one-third of all leaflets fulfilled approximately half of the recommendations. Despite the available guidelines, most leaflets did not fulfil recommendations for design. The authors concluded that adequate design can improve legibility of information and can improve quality life for older and individuals with low vision.

Previous research was mostly based on guidelines and characteristics of English [10] and French [11] language for improving legibility of text for individuals with low vision. This study evaluated and described the level of legibility of prints in Croatian language based on the parameters: typeface, letter size, punctuation marks, highlighting style, colour contrast between letters and background. The aim of the paper is to propose optimal settings for design of Croatian text adapted for readers with low vision. 


\section{Methods}

For the purposes of this research a continuous text in Croatian language was designed in the form of two samples. The following parameters were included:

- Typeface: Minion Pro (serif typography) and Calibri (sans serif typography)

- Letter size: 12 pt, 16 pt, 18 pt, 20 pt, 22 pt, 24 pt, $26 \mathrm{pt}, 32 \mathrm{pt}$ and $36 \mathrm{pt}$

- Letter colour: white, black (90\%), yellow (70\%), red (100\% magenta, 100\% yellow), blue ( $40 \%$ cyan, $5 \%$ magenta), green $(60 \%$ cyan, $80 \%$ yellow)

- Background colour: white, black (90\%), yellow (25\%)

- Magnification of punctuation marks: 0\%, $50 \%$ and $100 \%$

- Highlighting style: bold, underline, italic, small caps, all caps

Two sample categories were used: unadjusted sample (US) and customized sample (CS).

In the unadjusted sample (US) the text was designed for people with normal vision. Minion Pro was used, letter size $12 \mathrm{pt}$, leading 14,4 pt (120\% of the letter size).

Text was divided into the three units (USU) with regard to the different letter colour and background colour:

- 1. USU - white letter colour on black background

- 2. USU - black letter colour on white background

- 3. USU - red letter colour on yellow background.

In the customized sample (CS) the text was adapted for people with low vision. Sans serif typography Calibri was used in different letter sizes, leading $120 \%$ of the letter size. The text was divided into 13 units (CSU) based on the parameters shown in Table 1.

Table 1. - The parameters of customized sample units (CSU)

\begin{tabular}{|l|c|c|c|}
\hline $\begin{array}{l}\text { Customized } \\
\text { sample units }\end{array}$ & $\begin{array}{c}\text { Letter } \\
\text { colour }\end{array}$ & $\begin{array}{c}\text { Letter } \\
\text { size }(\mathbf{p t})\end{array}$ & $\begin{array}{c}\text { Background } \\
\text { colour }\end{array}$ \\
\hline 1. CSU & black & 16 & yellow \\
\hline 2. CSU & black & 18 & white \\
\hline 3. CSU & white & 18 & black \\
\hline 4. CSU & blue & 20 & black \\
\hline 5. CSU & black & 22 & white \\
\hline 6. CSU & blue & 22 & white \\
\hline
\end{tabular}

\begin{tabular}{|l|c|c|c|}
\hline $\begin{array}{l}\text { Customized } \\
\text { sample units }\end{array}$ & $\begin{array}{c}\text { Letter } \\
\text { colour }\end{array}$ & $\begin{array}{c}\text { Letter } \\
\text { size }(\mathbf{p t})\end{array}$ & $\begin{array}{c}\text { Background } \\
\text { colour }\end{array}$ \\
\hline 7. CSU & yellow & 22 & black \\
\hline 8. CSU & green & 22 & black \\
\hline 9. CSU & blue & 24 & white \\
\hline 10. CSU & white & 26 & black \\
\hline 11. CSU & red & 26 & black \\
\hline 12. CSU & red & 32 & white \\
\hline 13. CSU & white & 36 & black \\
\hline
\end{tabular}

\subsection{Participants}

The research was conducted in The Association of Blind People Zagreb which is constituted of approximately 100 members. Regardless the large number of blind members, only seven subjects participated in the interview, age range 60-80 years (mean age 72.3 years). The remaining vision percentage of the participants that took part in the interview was $2-5 \%$ with additional diagnosed eye defects. The investigation was carried out through a structured interview in a separate well-illuminated room during one day. The average duration of the interview was approximately 20 minutes. Each participant independently read and reviewed two samples: unadjusted sample (US) and customized sample (CS) and discussed with the interviewer about the legibility and readability of the text. Questions were simple and unambiguous. The interview was recorded with a dictaphone for better analysis and also a transcript was made.

\section{Results}

In this research the unadjusted and customized text for people with low vision was evaluated by 7 participants who had different percentage of remaining vision and different eye defects.

1. participant - female, age 76 , remaining vision $5 \%$, uses magnifying glass for reading (magnification $12 \mathrm{x}$ ). She could not read unadjusted sample because the letter size was too small (12 pt). On different backgrounds (black and 25\% yellow) the text was equally illegible. The text was legible when reading the customized sample, white letters on black background and vice versa. The participant was able to read the text in black colour on yellow background but with more straining than on the white background. The red and blue text on black background were not legible even though they were the same size like the text in black colour on yellow background. Punctuation marks were read 
with no difficulties with a note that some marks were overly exaggerated even for people with $5 \%$ remaining vision (there was a $100 \%$ magnification). For highlighting style, the participant discussed that adding bold is the only useful way. Other highlighting style (especially italic) decreased the legibility.

2. participant - female, age 70 , remaining vision $5 \%$, uses contact lenses. She was able to read the unadjusted sample with high level of concentration and noted that the small letters (12 pt) were much easier to read when in negative (white text on black background). The text on the customized sample was more legible on the yellow than on the white background (in the case of black colour of letters), but was not able to read the red and blue text on the black background no matter the size. The participant was successful in reading the red text on white background.

3. participant - female, age 60 , retinal detachment of the right eye (no vision) and remaining vision on left eye $5 \%$. Both samples were read with vision-enhancement aids. She couldn't read the unadjusted sample. The participant was able to read the customized sample from the distance of $1-2 \mathrm{~cm}$ and noted that it was easier and that she is used to read black letters on white background but was also able to read yellow and green text on black background and black text on yellow background. Magnificated punctuation marks facilitated her reading, but only when moderately emphasized. Overly exaggerated marks (100\% magnification) were noted to be unnecessary.

4. participant - female, age 80 , remaining vision $5 \%$, did not use a magnifying glass for reading. The participant was able to read black text on white background on the unadjusted sample, but very slowly. The punctuation marks had good visibility and did not have to be emphasized. The customized sample with $16 \mathrm{pt}$ letter size was easily read. White background was most suited and the participant registered a big difference between black and white backgrounds. Yellow text on black background was easily read when compared with red and green lettering that were completely illegible no matter the size. The participant noted that all caps and bold were the best highlighting styles while italic and underline decrease legibility.
5. participant - female, age 80 , remaining vision $5 \%$. The participant wears eyeglasses and uses magnifying glass (magnification 12x) when reading. Both samples were read from the distance of $25 \mathrm{~cm}$. The unadjusted sample was completely unreadable no matter the text colour or background. The participant could read the customized sample with white background and black text (18 pt) with a high level of concentration and very slowly. The participant also noted that she usually wouldn't read that text because it exhausts her. The participant could read the red and blue text on white background, but also with great difficulty. In her opinion, the red text had little contrast to the background. She also couldn't read the black text (16 pt) on yellow background. Actually, she read letter by letter with a very slow pace. The white text (larger than $20 \mathrm{pt}$ ) on black background was most suited for her. She could not read green, red and blue text, but she could read yellow. Some punctuation marks, like dots, were visible enough, but commas presented more difficulties. The participant noted that bold was the best option as highlighting style.

6. participant - male, age 74 , remaining vision $2 \%$. Besides partial blindness, he was diagnosed with nystagmus. This manifests as movement of the field of view (eye twitching). The participant read the samples with a magnifying glass (magnification 12x) from a distance of approximately $15 \mathrm{~cm}$. He could read the unadjusted sample (12 pt) but could not read the same text in italic. The subject read the text letter by letter because of the eye twitching which slowed down the reading rate. The black text on white background was much clearer than vice versa. The red letters on yellow background could not be read. The customized sample was read much better and faster, even in the case of the minimal letter size (18 pt). The participant read letters no matter the background colour. It was a bit more difficult to read when there was green and blue letters on black background. He could not read the red letters. The participant noted that there was no need to magnify punctuation marks. As a highlighting style, he noted that bold is the best option.

7. participant - female, age 74 , remaining vision $3 \%$, cataracts on left eye. The participant could not read the unadjusted sample. She read 
the customized sample from a close distance $(1-2 \mathrm{~cm})$. She could read black letters $(22 \mathrm{pt})$ on white background and all the other letters were with insufficient contrast. The participant could read white and yellow letters on black background. Larger letters helped with the reading, and the text smaller than $20 \mathrm{pt}$ was illegible. Underline as a highlighting style was confusing and words were foggy, so she concluded that bold was the best option.

The comparison of parameters upon which the legibility was evaluated between the unadjusted and customized samples for people with different percentage of remaining vision and medical diagnosis is show in Tables 2-4.

Table 2. - The legibility of the unadjusted sample (US)

\begin{tabular}{|c|c|c|c|c|c|c|c|}
\hline \multirow{2}{*}{$\begin{array}{l}\text { Sample units } \\
\text { Letter colour / } \\
\text { Background colour }\end{array}$} & \multicolumn{7}{|c|}{ Respondents } \\
\hline & 1 & 2 & 3 & 4 & 5 & 6 & 7 \\
\hline 1. USU - white / black & - & $+/-$ & - & - & - & $+!$ & - \\
\hline 2. USU - black / white & - & + & - & $+/-$ & - & + & - \\
\hline 3. USU - red / yellow & - & - & - & - & - & - & - \\
\hline $\begin{array}{l}+ \text { participant could re } \\
+/- \text { participant could } \mathrm{r} \\
\text { concentration and } \\
+ \text { participant could n } \\
+! \text { participant prefers } \\
\text { background }\end{array}$ & & & & & & & \\
\hline
\end{tabular}

Table 3. - The legibility of the customized sample (CS)

\begin{tabular}{|l|c|c|c|c|c|c|c|}
\hline Sample units & \multicolumn{7}{|c|}{ Respondents } \\
\cline { 2 - 8 } $\begin{array}{l}\text { Letter colour / Letter size } \\
\text { /Background colour }\end{array}$ & $\mathbf{1}$ & $\mathbf{2}$ & $\mathbf{3}$ & $\mathbf{4}$ & $\mathbf{5}$ & $\mathbf{6}$ & $\mathbf{7}$ \\
\hline 1. CSU - black /16/ yellow & + & + ! & + & + & $+/$ - & + & - \\
\hline 2. CSU - black /18/ white & + & + & + & + & $+/$ - & + & - \\
\hline 3. CSU - white /18/ black & + & + & + & $+/$ & - & + & - \\
\hline 4. CSU - blue /20/ black & - & + & + & $+/$ & - & $+/$ & - \\
\hline 5. CSU - black /22/ white & + & + & + & + ! & + & + & + \\
\hline 6. CSU - blue /22/ white & + & - & + & + & $+/-$ & + & - \\
\hline 7. CSU - yellow /22/ black & + & + & + & + ! & + & + & + \\
\hline 8. CSU - green /22/ black & + & + & + & - & - & $+/-$ & - \\
\hline 9. CSU - blue /24/ white & + & - & + & + & $+/-$ & + & - \\
\hline 10. CSU - white /26/ black & + & + & + & + & + & + & + \\
\hline 11. CSU - red /26/ black & - & - & - & - & - & - & - \\
\hline 12. CSU - red /32/ white & + & + & - & + ! & + /- & + & - \\
\hline 13. CSU - white /36/ black & + & + & + & + & + & + & + \\
\hline
\end{tabular}

Table 4. - Highlighting style and magnification of punctuation marks

\begin{tabular}{|l|c|c|c|c|c|c|c|}
\hline & \multicolumn{7}{|c|}{ Respondents } \\
\hline Highlighting style & $\mathbf{1}$ & $\mathbf{2}$ & $\mathbf{3}$ & $\mathbf{4}$ & $\mathbf{5}$ & $\mathbf{6}$ & $\mathbf{7}$ \\
\hline Bold & + & + & + & + & + & + & + \\
\hline Italic & - & - & - & - & - & - & - \\
\hline Small caps & - & - & - & - & - & - & - \\
\hline
\end{tabular}

\begin{tabular}{|l|c|c|c|c|c|c|c|}
\hline & \multicolumn{7}{|c|}{ Respondents } \\
\hline Highlighting style & $\mathbf{1}$ & $\mathbf{2}$ & $\mathbf{3}$ & $\mathbf{4}$ & $\mathbf{5}$ & $\mathbf{6}$ & $\mathbf{7}$ \\
\hline All caps & - & - & - & + & - & - & - \\
\hline Underline & - & - & - & - & - & - & - \\
\hline $\begin{array}{l}\text { Magnification of } \\
\text { punctuation marks (\%) }\end{array}$ & \multicolumn{7}{|c|}{} \\
\hline 0 & - & + & - & + & - & + & - \\
\hline 50 & + & + & + & - & + & - & + \\
\hline 100 & + & + & - & - & + & - & + \\
\hline
\end{tabular}

\section{Discussion}

In this paper two sample texts were used to test the level of legibility for people with low vision. The level of legibility was observed using parameters like typeface and letter size, magnification of punctuation marks, highlighting styles and different colours of letters and background.

The first sample was formed according to guidelines for people of normal vision [12], with different colour of text and background. The results showed that serif typography of 12 pt was evaluated as illegible for the most of participants. Two participants read the texts with maximal contract between letter and background (black-white, white-black) with great difficulty, while in the case with lower contrast (red-yellow) no participants could read the text (Table 2).

The second sample was designed according to guidelines of the American Printing House for the Blind (APH), Royal National Institute of Blind People (RNIB) and Canadian National Institute for the Blind (CNIB). According to those guidelines different letters size were used, colour of text and background, magnification of punctuation marks and highlighting styles. According to the CNIB a sans serif typography was used with the smallest size of $16 \mathrm{pt}$. The black letter size of $16 \mathrm{pt}$ on yellow background allowed legibility of the text for the most of the participants. Letter size of $22 \mathrm{pt}$ enabled better legibility for the most of the participants, but this depended on the text colour and background. All the participants could read white text of $26 \mathrm{pt}$ and larger on black background. The letter size of $22 \mathrm{pt}$ enabled legibility of the text for the people with low vision with the adequate contrast between letter colour and background (Table 3). 
The relation between letter and background had bigger influence on legibility than the letters size. Decreased contrast showed a negative influence on legibility of the text. No matter the background, the blue text colour (white or black), in letter size of 22-24 pt, was not legible enough for the half of the participants. Green text colour, size $22 \mathrm{pt}$, on black background also decreased the legibility of the text for the half of the participants. Red text on black background with the letter size of $26 \mathrm{pt}$ presented itself as the worst combination where none of the participants could read the text. The combination of red text on white background with letter size of $32 \mathrm{pt}$ was slightly better. According to these results, it can be noted that the contrast between the letter colour and background needs to be higher in order to increase legibility (Table 3 ). The guidelines of CINB and RINB suggest using white text colour on black background as the highest contrast which is confirmed in these findings as well.

The best highlighting style was bold which was noted by all of the participants. Italic, small caps, all caps and underlined were graded and unacceptable, making the text more difficult to read (Table 4). Magnification the punctuation marks was acceptable for the half of the participants, but with a maximum of $50 \%$ increase. Larger increases of the punctuation marks were noted as fake and exaggerated (Table 4).

According to the obtained results, it is shown that the relation of the letter colour and background, or better yet contrast has the biggest influence on the legibility for people with low vision. Smaller influence on the legibility has the letter size and even smaller the typeface. As a highlighting style, bold is recommended.

\section{Conclusion}

Textual information is mostly designed for people with normal vision, with an aim of meeting the aesthetic criteria and trends. Printed media often uses different combinations of text and background colours which decrease legibility. Also, they tend to use smaller letter size in order to fit the text in the limited space. In this way, they completely exclude the population of visual impaired individuals because of the difficulties they face when reading those types of texts. Special consideration should be taking when designing flyers about medicine and pharmaceutical products which are mostly targeted towards elder population with low vision. Guidelines for designing printed media for people with impaired eyesight could be useful in order to enable them to read information as other members of society.

\section{References:}

1. Arditi, A., Cho, J., 2005. Serifs and font legibility. Vision Res., 45 (23), 2926-2933.

2. Nini, P., 2006. Typography and the Aging Eye: Typeface Legibility for Older Viewers with Vision Problems. [cited 2017 May 10] Available from: http://www. aiga.org/typographyand-the-aging-eye

3. Arditi, A., Cho, J., 2007. Letter case and text legibility in normal and low vision. Vision Res., 47 (19), 24992505.

4. Mansfield, J.S., Ahn, S.J., Legge, G.E., Luebker, A., 1993. A new reading-acuity chart for normal and low vision. Ophthal Physiol Opt., 3, 232-235.

5. Kitchel, J.E., APH Guidelines for Print Document Design, American Prining House for the Blind. [cited 2018 January 30] Available from: http://www.aph.org/ research/design-guidelines

6. https://www.myfonts.com/fonts/bitstream/tiresias/ [cited 2018 February 10]

7. Tarita-Nistor, L., Lam, D., Brent, M.H., Steinbach, M.J., Gonzalez, E.G., 2013. Courier: a better font for reading with age-related macular degeneration, Can J Ophthalmol., 48 (1), 56-62.

8. Rubin, G.S., Feely, M., Perera, S., Ekstrom, K., Williamson, E., 2006. The effect of font and line width on reading speed in people with mild to moderate vision loss. Ophthalmic Physiol Opt. 26 (6), 545-554.

9. Canadian National Institute for the Blind.Clear Print Design Standard. [cited 2018 February 15] Available from: http://www.cnib.ca/en/services/resources/ clearprint/Pages/default.aspx

10. Chubaty, A., Sadowski, C.A., Carrie, A.G., 2009. Typeface legibility of patient information leaflets intended for community-dwelling seniors. Age Ageing, 38 (4), 441-447.

11. Russell-Minda, E., Jutai, J.W., Strong, J.G., Campbell, K.A., Gold, D., Pretty, L., Wilmot, L., 2007. The legibility of Typefaces for readers with low vision: A research review. Journal of Visual Impairment \& Blindness, 101 (7), 402-415.

12. Tarasov, D.A., Sergeev, A.P., Filimonov, V.V., 2015. Legibility of textbooks: a literature review. Procedia Social and Behavioral Sciences, 174, 1300-1308. 